\title{
Spacing One's Study: Evidence for a Metacognitive Control Strategy
}

\author{
Lisa K. Son \\ Barnard College
}

\begin{abstract}
This article investigated individual control of spacing strategies during study. Three predictions were outlined: The spacing hypothesis suggests that people choose to space their study to improve long-term learning via the spacing effect. The massing hypothesis suggests that people choose to mass their study because of illusions of confidence during study. The metacognitive hypothesis suggests that people control their spacing schedules as a function of their metacognitive judgments of specific to-be-learned items. To test these hypotheses, the authors asked participants to study and make judgments of learning for cue-target pairs. Then, participants were given three choices; they could study the pair again immediately (massed), study the pair again after the entire list had been presented (spaced), or choose not to restudy (done). Results supported a metacognitively controlled spacing strategy-people spaced items that were judged to be relatively easy but massed items that were judged as relatively difficult.
\end{abstract}

Students seem to have an immensely difficult time avoiding cramming. In the psychological literature, cramming has been better known as massing, in which the learner studies a particular to-be-learned item for a certain period of time with short rest periods, or lags, between study trials. By contrast, studying the to-be-learned item over several repetitions with longer lags between them has been known as spacing. It has been found extensively that spacing leads to higher performance than does massing, particularly under conditions in which the delay between study and test is long rather than short (Bahrick, Bahrick, Bahrick, \& Bahrick, 1993; Bahrick \& Phelps, 1987; Cahill \& Toppino, 1993; Dempster, 1987, 1988; Glenberg, 1976, 1977, 1979; Glenberg \& Lehmann, 1980; Glover \& Corkill, 1987; Hintzman, 1974; Jensen \& Freund, 1981; Melton, 1970; Rea \& Modigliani, 1987; Shaughnessy, Zimmerman, \& Underwood, 1972; Toppino, 1991, 1993; Underwood, 1970; Zechmeister \& Shaughnessy, 1980). This classic spacing effect was first discovered by Ebbinghaus, who used himself as a subject (Ebbinghaus, 1885), and has received wide attention over the past 30 years or so in the laboratory. But surprisingly, in all of the published studies, the lags between the study trials were controlled by the experimenters rather than by the participants themselves. An issue that has scarcely been mentioned in the spacing literature is the extent to which one has control over one's spacing strategies. Glenberg (1977) proposed that organizational strategies might contribute to how an individual might space his or her study. Zechmeister and Shaughnessy (1980) suggested that participants might allocate their study resources in accordance with metamemory judgments about how well items are learned. However, control of spacing has not been investigated above and beyond these suggestions. The question of interest here was to consider and test how people might control their spacing using a metacognitively controlled strategy for each item.

This research was supported by startup funds from the Department of Psychology of Barnard College. Thanks to Natalia Chan, Louise Hogan, and Danielle Sussan for help in collection of the data.

Correspondence concerning this article should be addressed to Lisa K. Son, Department of Psychology, Barnard College, 3009 Broadway, New York, NY 10027. E-mail: 1son@barnard.edu
In light of the overwhelming evidence for the spacing effect, a strategy that people might use to control study could be to space as many of the to-be-learned items as they can; this is the spacing hypothesis. Thus, one seemingly optimal strategy might be to space all to-be-learned items. However, there is also evidence that might lead the learner astray from the seemingly optimal alwaysspace strategy. Although typically people have been forced into a massed versus spacing paradigm, acquisition is slower for the spaced items than it is for the massed items (although at final test, the spacing effect still transpires; Bahrick et al., 1993; Simon \& Bjork, 2001; Zechmeister \& Shaughnessy, 1980). These data have also, in fact, shown that people report higher confidence after massed trials than they do after spaced trials. Researchers have also suggested that when items are massed, participants may be misled to believe that encoding occurred on the initial presentation and that further work on the item is not needed. Thus, participants may choose to ignore massed presentations, presumably because they believe that the to-be-learned information is already currently available, and further study will add little benefit (Jacoby, 1978; Simon \& Bjork, 2001). In short, people may be exhibiting an overconfidence effect on massed items, which in turn may influence their study strategies. Specifically, people's strategies may be to mass their learning trials because they believe that their learning rate is faster; this is what I call the massing hypothesis.

Thus far, the two hypotheses described are general strategies that would not differ from item to item. For example, using the massing strategy, regardless of the difficulty of each to-be-learned item, individuals would always choose to cram their study. And, using the spacing strategy, individuals would always space their study. It seems likely, though, that people may control their spacing decisions differentially from item to item based on their metacognitive knowledge of each item (e.g., how difficult the item is to learn). For example, if an item were well learned (i.e., high in metacognitive knowledge), then continuing to study that item would not be necessary, and instead, waiting a while before restudying that item might be an obvious strategy. On the other hand, if the item were not yet learned (i.e., low in metacognitive knowledge), then continuing to study now might be beneficial. 
This so-called metacognitive hypothesis is theoretically based on another type of studying strategy called the expanding practice method, in which a person first is tested on the to-be-remembered item at short lags and then, with successive tests, waits longer and longer before trying to retrieve the item (Birnbaum \& Eichner, 1971; Bjork, 1975; Glover, 1989; Landauer \& Bjork, 1978; Melton, 1970; Rea \& Modigliani, 1985; Whitten \& Bjork, 1977). Researchers have said that the efficiency of the expanding practice method is due to the fact that after study, learners wait until the item is effortful to retrieve, but not impossible-which entails massed trials at the beginning of learning when retrieval is still untried and spaced trials later in learning when the item has already been retrieved successfully. And, if it is assumed that items become easier with the number of successful retrieval occurrences, people should choose to mass difficult items and space easy ones. The purpose of the following experiment was to test this metacognitive hypothesis - that the spacing strategy would be guided by an item's level of judged difficulty.

\section{Method}

\section{Participants}

Thirty-two Introductory Psychology students from Barnard College participated for course credit. Participants were treated in accordance with the ethical standards of the American Psychological Association.

\section{Materials}

The stimuli were 60 synonym pairs taken from a list of vocabulary words from the Graduate Record Examination (e.g., hirsute-hairy), randomly selected by the computer program for each participant. We hoped that, through random selection, a range of difficulty would be presented to each participant.

\section{Procedure}

Participants were presented with the list of word-synonym pairs to study for a later test. Each pair was presented for $1 \mathrm{~s}$. After each presentation, participants made judgments of learning (JOLs) for each of the pairs-for each item, participants were asked to make a rating of how confident they were that they would be able to recall the synonym when given only the word on a later memory test. Responses were made on a slider ranging from $0-100$. Before beginning the actual experiment, participants were given a practice session for making JOLs using the slider presented on the computer screen in which eight words that were not used in the experiment were presented.

After making their JOLs, subjects were given three buttons on the screen: "Study Now," "Study Later," and "Done." If "Study Now" (massed) was chosen, then the pair was presented again immediately for 3 s. If "Study Later" (spaced) was chosen, then that pair was shown again (for $3 \mathrm{~s}$ ) after the entire list had been presented. If the "Done" button was chosen, then that pair was not shown again at all. After the entire list had been presented-some massed and some spaced, some only once-there was a 15-min distractor task in which participants calculated multiplication problems. Finally, there was a cued-recall test in which only the first word from each pair was presented. The participant's task was to type in the synonym for each word.

\section{Results}

A probability level of $p<.05$ was used as the criterion for statistical significance. Estimates of effect size, $d$, were calculated as partial eta squared. We analyzed the data using normalized JOL scores divided into six levels (vincentized into the top $1 / 6$, next $1 / 6$, etc.) for each participant. The metacognitive hypothesis predicted that participants' spacing strategies would depend on their JOLs, such that the higher an item's JOL, the more likely it would be that the item would be chosen for a spaced repetition.

\section{Spacing Strategy}

The proportions of items that were chosen as massed, spaced, and done for each JOL level are presented in Figure 1. An analysis of variance (ANOVA) with spacing strategy (massed, spaced, and done) and JOL level (1-6) was conducted, resulting in a significant effect of spacing strategy, $F(2,240)=15.53, M S E=9.27$, $d=0.39$, indicating that, on the whole, people chose to restudy more often than not and chose to space more often than mass. Furthermore, there was a significant interaction between spacing strategy and JOL level, $F(10,240)=4.05, M S E=0.37, d=$ 0.14 - as JOL level increased, the proportion of spaced and done items increased, whereas the proportion of massed items decreased-supporting the metacognitive hypothesis.

Although the "Done" option allowed participants to select not to restudy a particular item, how a person controls when to restudy an item was the original interest of this study. And although the proportion of spaced items increased as JOL level increased, this did not occur at the highest level of JOL, essentially because of the drastic increase in the number of items that were not selected for restudy. Thus, a similar analysis was conducted on only those items that were restudied-items that were selected for massed or spaced study - given that study was not yet done. When doing so, the number of spaced items increased steadily (whereas the number of massed items decreased steadily) as JOL increased-the proportions of spaced items for JOL levels $1-6$ were $0.49,0.54$, $0.60,0.62,0.68$, and 0.69 , respectively. Thus, when an item is not yet designated as being done, the higher a person's JOL level, the more likely it is that the item is chosen for spaced study than for massed study. The interaction between JOL level and spacing was significant, $F(5,120)=2.49, M S E=0.32, d=0.09$ - again suggesting metacognitive control of spacing.

\section{Final Test Performance}

Although the above analysis was the main question of interest here, mean proportion correct at final test was calculated separately for each JOL level and for each type of spacing. For example, among the items that comprised the highest JOL level of 6 and were massed, only $9 \%$ of those items were recalled at final test. Among those items that comprised the highest level of 6 but were spaced, $31 \%$ were recalled correctly at final test. The proportions of the items for each condition that were recalled at final test are displayed numerically above each bar in Figure 1. As can be seen, a spacing effect occurred at each JOL level-items judged as similar in difficulty were remembered better after spaced practice than after massed practice. However, note that because the retention interval was only $15 \mathrm{~min}$, by definition, all of the spaced items were studied closer in time to the final test. Thus, it is unclear that the data provide evidence for the spacing effect. Further issues are discussed in the Discussion section. 


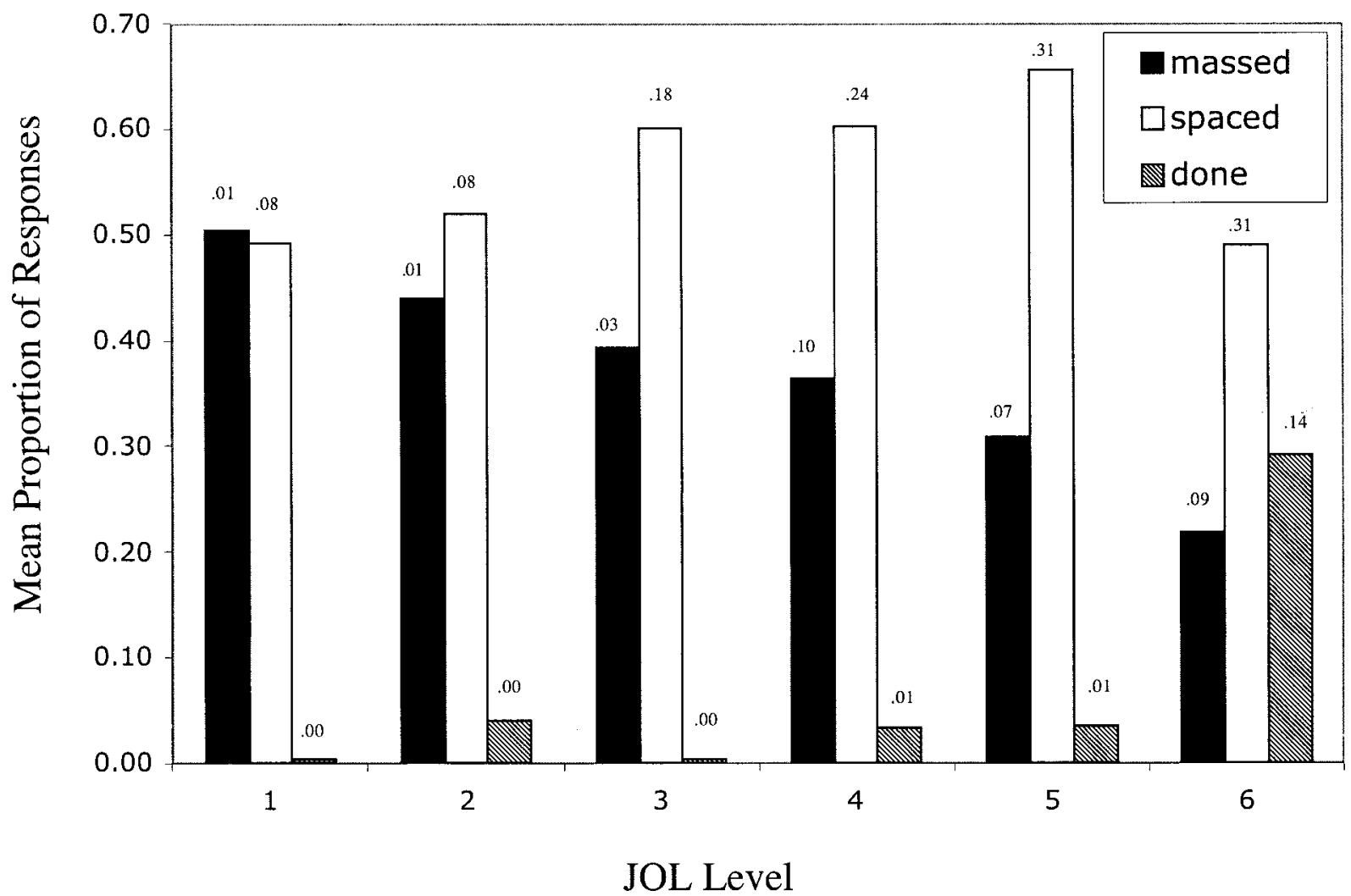

Figure 1. The bars represent the mean proportion of massed (solid bars), spaced (white bars), and done (hatched bars) items across judgment of learning (JOL) level ( $z$ scores calculated for each participant and split into six levels, from least confident to most confident). The numbers above each bar represent the proportion of those items that were recalled correctly at final test. For example, of those items at JOL Level 6 and selected for massed study, only $9 \%$ were correctly recalled at final test.

\section{Discussion}

The main investigation here was to see how people chose to space their study trials. The results supported the metacognitive hypothesis: People had an item-specific spacing strategy in which items that were judged as difficult were more often massed, whereas items that were judged as easier were more often spaced. People did not choose to mass all of the items, although previous research has shown that people believe that learning is faster during massed trials than it is during spaced trials. And people did not choose to space all of the items, providing some uncertainty as to the dominance of the spacing effect and its relation to selfcontrolled study. Instead, people's spacing strategies were guided more strongly by the judged difficulty of each item. These data provide additional support for the general assumption that people might use their metacognitive judgments to guide study behavior, whether it consists of spacing strategies, study-time allocation, or some other study behavior.

\section{Domain Limitations and Remaining Questions}

Researchers have been interested in the spacing effect for more than 100 years. However, how people actually control their own spacing has been unknown until now. The findings presented here suggest that the spacing effect literature should be revisited, focusing on the learner's point of view. These investigations introduce a new domain of questions. For example, although the data may provide some evidence that a spacing effect exists when holding judged difficulty constant, the effect might be due to the fact that the spaced items were studied closer in time to the final test. Thus, in future experiments, an equal retention interval for massed and spaced items should be used. Along similar lines, another limitation of this study was that participants were not aware of the retention interval. It is still an open question whether people's strategies might depend on their knowledge of the length of the retention interval.

Another question that still needs testing is how general the metacognitively controlled strategy is. For example, spacing choices may change with the level of encoding during the first presentation. For example, if an item is very easy, yet presented for such a short time that adequate encoding could not occur, then continued study - massing - might be optimal. Similarly, if a difficult item were presented for a long time so that encoding was adequate, then waiting a while_-spacing — might be more beneficial. Indeed, it was shown that if the first presentation time was increased to $3 \mathrm{~s}$, most of the items were chosen for spaced study (Son, 2002). Also, spacing strategies might depend on the overall 
level of difficulty of the to-be-learned items and the choices available. For example, in an experiment using the same method but excluding the "Done" option, some participants used an opposite metacognitive strategy of massing the easy items and spacing the difficult items, presumably because the items were all too easy and they wanted to get the easy ones over with instead of having to restudy them again later (Son, 2002). Other yet uninvestigated factors, such as level of expertise, motivation, time pressure, type of test, type of materials, and type of study (to name a few), could be influencing spacing strategies. The results presented here, then, are only the beginning of the investigation of people's control of spacing strategies and necessitate much further study.

\section{References}

Bahrick, H. P., Bahrick, L. E., Bahrick, A. S., \& Bahrick, P. E. (1993). Maintenance of foreign language vocabulary and the spacing effect. Psychological Science, 4, 316-321.

Bahrick, H. P., \& Phelps, E. (1987). Retention of Spanish vocabulary over 8 years. Journal of Experimental Psychology: Learning, Memory, and Cognition, 13, 344-349.

Birnbaum, I. M., \& Eichner, J. T. (1971). Study versus test trials and long-term retention in free-recall learning. Journal of Verbal Learning and Verbal Behavior, 10, 516-521.

Bjork, R. A. (1975). Short-term storage: The ordered output of a central processor. In F. Restle, R. M. Shiffrin, N. J. Castellan, H. R. Lindman, \& D. B. Pisoni (Eds.), Cognitive theory (Vol. 2, pp. 151-171). Hillsdale, NJ: Erlbaum.

Cahill, A., \& Toppino, T. C. (1993). Young children's recognition as a function of the spacing of repetitions and the type of study and test stimuli. Bulletin of the Psychonomic Society, 31, 481-484.

Dempster, F. N. (1987). Effects of variable encoding and spaced presentations on vocabulary learning. Journal of Educational Psychology, 79, 162-170.

Dempster, F. N. (1988). Retroactive interference in the retention of prose: A reconsideration and new evidence. Applied Cognitive Psychology, 2, $97-113$

Ebbinghaus, H. (1885). Memory: A contribution to experimental psychology. New York: Teachers College, Columbia University.

Glenberg, A. M. (1976). Monotonic and nonmonotonic lag effects in paired-associate and recognition memory paradigms. Journal of Verbal Learning and Verbal Behavior, 15, 1-16.

Glenberg, A. M. (1977). Influences of retrieval processes on the spacing effect in free recall. Journal of Experimental Psychology: Human Learning and Memory, 3, 282-294.

Glenberg, A. M. (1979). Component-levels theory of the effects of spacing of repetitions on recall and recognition. Memory \& Cognition, 7, 95112.

Glenberg, A. M., \& Lehmann, T. S. (1980). Spacing repetitions over 1 week. Memory \& Cognition, 8, 528-538.
Glover, J. A. (1989). The "testing" phenomenon: Not gone but nearly forgotten. Journal of Educational Psychology, 81, 392-399.

Glover, J. A., \& Corkill, A. J. (1987). Influence of paraphrased repetitions on the spacing effect. Journal of Educational Psychology, 79, 198-199.

Hintzman, D. L. (1974). Theoretical implications of the spacing effect. In R. L. Solso (Ed.), Theories in cognitive psychology: The Loyola Symposium (pp. 77-99). Hillsdale, NJ: Erlbaum.

Jacoby, L. L. (1978). On interpreting the effects of repetition: Solving a problem versus remembering a solution. Journal of Verbal Learning and Verbal Behavior, 17, 649-667.

Jensen, T. D., \& Freund, J. S. (1981). Persistence of the spacing effect in incidental free recall: The effect of external list comparisons and intertask correlations. Bulletin of the Psychonomic Society, 18, 183-186.

Landauer, T. K., \& Bjork, R. A. (1978). Optimal rehearsal patterns and name learning. In M. M. Gruneberg, P. E. Morris, \& R. N. Sykes (Eds.), Practical aspects of memory (pp. 625-632). London: Academic Press.

Melton, A. W. (1970). The situation with respect to the spacing of repetitions and memory. Journal of Verbal Learning and Verbal Behavior, 9 , $596-606$

Rea, C. P., \& Modigliani, V. (1985). The effect of expanded versus massed practice on the retention of multiplication facts and spelling lists. Human Learning: Journal of Practical Research and Applications, 4, 11-18.

Rea, C. P., \& Modigliani, V. (1987). The spacing effect in 4- to 9-year old children. Memory \& Cognition, 15, 436-443.

Shaughnessy, J. J., Zimmerman, J., \& Underwood, B. J. (1972). The spacing effect in the learning of word pairs and the components of word pairs. Memory \& Cognition, 2, 742-748.

Simon, D. A., \& Bjork, R. A. (2001). Metacognition in motor learning. Journal of Experimental Psychology: Learning, Memory, and Cognition, 27, 907-912.

Son, L. K. (2002, November). Metacognitively-controlled spacing of study. Paper presented at the annual meeting of the Psychonomic Society, Kansas City, MO.

Toppino, T. C. (1991). The spacing effect in young children's free recall: Support for automatic-process explanations. Memory \& Cognition, 19, 159-167.

Toppino, T. C. (1993). The spacing effect in preschool children's free recall of pictures and words. Bulletin of the Psychonomic Society, 31, $27-30$.

Underwood, B. J. (1970). A breakdown of the total-time law in free-recall learning. Journal of Verbal Learning and Verbal Behavior, 9, 573-580.

Whitten, W. B., II, \& Bjork, R. A. (1977). Learning from tests: Effects of spacing. Journal of Verbal Learning and Verbal Behavior, 16, 465-478.

Zechmeister, E. B., \& Shaughnessy, J. J. (1980). When you know that you know and when you think that you know but you don't. Bulletin of the Psychonomic Society, 15, 41-44.

Received December 24, 2002

Revision received October 27, 2003

Accepted November 4, 2003

\section{E-Mail Notification of Your Latest Issue Online!}

Would you like to know when the next issue of your favorite APA journal will be available online? This service is now available to you. Sign up at http://watson.apa.org/ notify/and you will be notified by e-mail when issues of interest to you become available! 